\title{
Comparison of anthropometric and training characteristics between recreational male marathoners and 24-hour ultramarathoners
}

This article was published in the following Dove Press journal:

Open Access Journal of Sports Medicine

19 October 2012

Number of times this article has been viewed

Christoph Alexander Rüst ${ }^{\prime}$

Beat Knechtle ${ }^{1,2}$

Patrizia Knechtle ${ }^{2}$

Thomas Rosemann'

'Institute of General Practice and for Health Services Research, University of Zurich, Zurich, ${ }^{2}$ Gesundheitszentrum St Gallen, St Gallen, Switzerland
Correspondence: Beat Knechtle Facharzt FMH für Allgemeinmedizin, Gesundheitszentrum St Gallen, Vadianstrasse 26, 900 I St Gallen, Switzerland

Tel +4I 07 I 2268282

Fax +4I 07 I2268272

Email beat.knechtle@hispeed.ch
Background: Of the anthropometry and training variables used to predict race performance in a 24-hour ultrarun, the personal best marathon time is the strongest predictor in recreational male 24-hour ultramarathoners. This finding raises the question of whether similarities exist between male recreational 24-hour ultramarathoners and male recreational marathoners.

Methods: The association between age, anthropometric variables (ie, body mass, body height, body mass index, percent body fat, skeletal muscle mass, limb circumference, and skinfold thickness at the pectoral, mid axillary, triceps, subscapular, abdominal, suprailiac, front thigh, and medial calf sites), previous experience and training characteristics (ie, volume, speed, and personal best time), and race time for 79 male recreational 24-hour ultramarathoners and 126 male recreational marathoners was investigated using bivariate and multivariate analysis.

Results: The 24-hour ultramarathoners were older $(P<0.05)$, had a lower circumference at both the upper arm $(P<0.05)$ and thigh $(P<0.01)$, and a lower skinfold thickness at the pectoral, axillary, and suprailiac sites $(P<0.05)$ compared with the marathoners. During training, the 24-hour ultramarathoners were running for more hours per week $(P<0.001)$ and completed more kilometers $(P<0.001)$, but were running slower $(P<0.01)$ compared with the marathoners. In the 24-hour ultramarathoners, neither anthropometric nor training variables were associated with kilometers completed in the race $(P>0.05)$. In the marathoners, percent body fat $(P<0.001)$ and running speed during training $(P<0.0001)$ were related to marathon race times.

Conclusion: In summary, differences in anthropometric and training predictor variables do exist between male recreational 24-hour ultramarathoners and male recreational marathoners for race performance.

Keywords: endurance, performance, athlete, body fat, skinfold thickness

\section{Introduction}

Ultramarathon running is very popular. ${ }^{1-4}$ Recent studies have shown an increase in participation in $161 \mathrm{~km}$ ultramarathons in recent years, in which master athletes have shown the greatest increases in participation. ${ }^{1-3}$ Several studies have attempted to define predictor variables for ultramarathon performance. ${ }^{5-15}$ Variables in physiology (eg, maximum oxygen uptake), ${ }^{14,15}$ anthropometry (eg, skinfold thickness, percent body fat), ${ }^{8,11,13}$ previous experience (eg, personal best times), ${ }^{6,9-12}$ and training (eg, running speed during training $)^{8-12}$ seem to have an influence on race outcome in ultramarathoners. In addition, age seems to affect ultramarathon performance. ${ }^{8,16}$ Different types of races exist in ultramarathon running. Athletes can participate in single-stage $\mathrm{e}^{17}$ or multistage ${ }^{18}$ races, in which they have to cover a given distance in the shortest possible time. However, other ultramarathons exist where the participants have to complete the longest distance 
possible within a given time. These are 6-hour, 12-hour, 24-hour, 48-hour, and 72-hour ultramarathons. ${ }^{19}$

Amongst the variables in both anthropometry and training predictive of race performance in a 24-hour ultramarathon, personal best marathon time has been reported to be a strong predictive variable for male recreational 24-hour ultramarathoners. ${ }^{5,12}$ This finding raises the question of whether similarities exist between male recreational 24-hour ultramarathoners and male recreational marathoners. For runners up to the marathon distance, different variables have been shown to correlate with running performance. Regarding physiological variables, the lactate value at both $10 \mathrm{~km} /$ hour and $22 \mathrm{~km} /$ hour running speeds ${ }^{20}$ and maximum oxygen uptake ${ }^{21}$ were associated with running performance. For anthropometric characteristics, body mass ${ }^{22,23}$ and lower limb skinfold thickness ${ }^{24,25}$ correlated with running performance. Considering training variables, the number of previously completed marathons, ${ }^{22}$ number of daily workouts, ${ }^{21,22}$ number of training runs of long duration, ${ }^{21}$ mean running distance per week, ${ }^{21}$ mean number of kilometers run per day, ${ }^{21}$ longest running distance covered per training session, ${ }^{26}$ duration of training, ${ }^{22}$ kilometers run per week, ${ }^{22,36}$ and running speed during training ${ }^{22,27}$ have been associated with running performance.

A recent study comparing $100 \mathrm{~km}$ ultramarathoners and marathoners showed that age, body mass, and percent body fat were positively related and kilometers run per week were negatively related to $100 \mathrm{~km}$ race times in ultramarathoners. ${ }^{28}$ However, in the marathoners, percent body fat was positively associated and speed in running training was negatively associated with marathon race times. Because both anthropometric and training variables were related to race performance in both $100 \mathrm{~km}$ ultramarathoners and marathoners, ${ }^{28}$ we investigated whether male recreational 24-hour ultramarathoners and male recreational marathoners were similar regarding their anthropometry and training. In a 24-hour ultramarathon, athletes achieve distances of approximately $150 \mathrm{~km} \cdot{ }^{12,13}$ Our hypotheses were, firstly, that the two groups of athletes would show no significant differences in either their training parameters or anthropometric measurements and, secondly, that anthropometric characteristics, such as body fat, and training characteristics, including running speed during training, would be related to performance in both groups of athletes.

\section{Materials and methods Subjects}

All male ultramarathoners in the 24-hour Basel ultramarathon and all male runners in the Basel marathon in
Switzerland were informed about the planned investigation via an electronic newsletter sent by the organizer 3 months before the start of the race. We focused on recreational male athletes, defined as athletes pursuing a regular occupation, performing sport during leisure time, having no sponsors, and not earning their livelihood through sponsorship or prize money. A total of 79 subjects were recruited for the 24-hour Basel ultramarathon, where athletes were recruited in two consecutive years from 2010 to 2011. For the Basel marathon, a total of 126 male marathoners were investigated prerace. The study was approved by the institutional review board for use of human subjects at the Canton of St Gallen, Switzerland. The athletes were informed of the experimental procedures and gave their informed written consent to participate. No athlete was included twice and no athlete competed in both races.

\section{Races}

The 24-hour Basel ultramarathon takes place every year in mid May. Ultramarathoners from all over Europe start at noon, and perform as many laps as possible on a flat course over 24 hours to achieve the longest distance possible. Each lap of $1.141 \mathrm{~km}$ is counted by a personal lap counter for each runner. The 24-hour ultramarathoners had the opportunity to consume food and beverages ad libitum from an abundant buffet provided by the organizer. If preferred, they could also ingest food provided by their personal support crews. The support crews were also allowed to help with changing clothes and shoes. In the Basel marathon, the athletes had to run two laps on asphalt at an altitude of $200 \mathrm{~m}$. The organizer offered food and fluids at aid stations. Because the participation rate in an ultramarathon race is low, ${ }^{1-4,29}$ data were collected from the 24-hour Basel ultramarathon during four consecutive years (2008-2011), to increase the sample size for 24-hour ultramarathoners.

\section{Anthropometric measurements}

The afternoon before the start of the race, anthropometric characteristics such as body mass, body height, limb circumference, and skinfold thickness at the pectoral, mid axillary, triceps, subscapular, abdominal, suprailiac, front thigh, and medial calf sites were measured. Limb circumference and skinfold thickness were measured on the right side of the body. Using these data, body mass index, percent body fat, and skeletal muscle mass were calculated by anthropometric methods. Body mass was measured using a commercial scale (Beurer BF 15, Beurer, Ulm, Germany) to the nearest $0.1 \mathrm{~kg}$. Body height was determined using a stadiometer to 
the nearest $0.01 \mathrm{~m}$ (Tanita HR 001 portable height measure, Tanita Europe, Amsterdam, The Netherlands). Limb circumference was measured using a nonelastic tape measure (KaWe CE, Kirchner und Wilhelm, Aspberg, Germany) to the nearest $0.1 \mathrm{~cm}$. The circumference of the upper arm was measured at the mid arm, the circumference of the thigh was taken at the mid thigh, and the circumference of the calf was measured at the mid calf. All skinfold data were obtained using a skin-fold caliper (GPM-Hautfaltenmessgerät, Siber and Hegner, Zurich, Switzerland) and recorded to the nearest $0.2 \mathrm{~mm}$. The skin-fold caliper measures with a pressure of $0.1 \mathrm{MPa} \pm 5 \%$ over the whole measuring range. The skinfold measurements were taken once for all eight skinfold sites, and the procedure was then repeated twice more by the same investigator, and the mean of three measurements was used for the analyses. The timing of skinfold measurement was standardized to ensure reliability. According to the method reported by Becque et al, readings were performed 4 seconds after applying the caliper. ${ }^{30}$ One trained investigator took all skinfold measurements because intertester variability is a major source of error in skinfold measurements. Intrarater and interrater agreement was assessed in 27 male runners prior to an ultramarathon, based on measurements taken by two experienced primary care physicians. ${ }^{31}$ The intraclass correlation (ICC) within the two raters was excellent for all anatomical sites measured and for various summary measurements of skinfold thicknesses (ICC > 0.9). Agreement tended to be higher within than between raters, but still showed excellent reliability (ICC $>0.9$ ) for the summary measurements of skinfold thickness. For the sum of eight skinfolds for measurer 1, bias (average difference between measure 1 and 2) was $-0.515 \mathrm{~mm}$, the standard deviation of the average difference was $1.492 \mathrm{~mm}$, and the $95 \%$ limits of agreement were between $-3.439 \mathrm{~mm}$ and $2.409 \mathrm{~mm}$.

\section{Estimation of body fat and skeletal muscle mass}

Percent body fat was estimated using the anthropometric formula devised by Ball et al for males where percent body fat $=0.465+0.180 \times(\Sigma 7 \mathrm{SF})-0.0002406 \times(\Sigma 7 \mathrm{SF})^{2}+$ $0.0661 \times($ age $)$, where $\Sigma 7 \mathrm{SF}$ is the sum of skinfold thickness for the pectoralis, axillary, triceps, subscapular, abdomen, suprailiac, and thigh sites (mean in $\mathrm{mm}$, age in years). ${ }^{32}$ The predicted residual sum of squares (PRESS) $r^{2}$ was high (0.90) and the PRESS standard error of estimates was excellent $(2.2 \%$ of the mean) for the equation when applied to a sample of 160 men. Skeletal muscle mass (SMM) was estimated using the formula of Lee et al, with $\mathrm{SMM}=\mathrm{Ht} \times\left(0.00744 \times \mathrm{CAG}^{2}+\right.$ $\left.0.00088 \times \mathrm{CTG}^{2}+0.00441 \times \mathrm{CCG}^{2}\right)+2.4 \times$ gender $0.048 \times$ age + race +7.8 , where $\mathrm{Ht}$ is height, $\mathrm{CAG}$ is skinfold-corrected upper arm girth, CTG is skinfold-corrected thigh girth, CCG is skinfold-corrected calf girth, gender $=1$ for male (age is in years, and race $=0$ for white men and 1 for black men). ${ }^{33}$ This equation was validated using magnetic resonance imagining (MRI) to determine skeletal muscle mass. There was a high correlation between the predicted skeletal muscle mass and the skeletal muscle mass measured by MRI $\left(r^{2}=0.83, P<0.0001\right.$, standard error of estimates $=2.9 \mathrm{~kg}$ ). The correlation between the measured and predicted skeletal muscle mass difference and the measured skeletal muscle mass was significant $\left(r^{2}=0.90, P=0.009\right)$.

\section{Training records}

Upon recruitment into the study 3 months before the start of both the 24-hour Basel ultramarathon and the Basel marathon, the subjects were asked to record their training units, showing duration in minutes and distance in kilometers, until the start of the race. The investigator provided an electronic file in which the subjects could insert each training unit with distance, duration, and speed, expressed in $\mathrm{km} /$ hour. The investigator then calculated the mean weekly hours, mean weekly kilometers run, and the mean speed per discipline during training in the prerace preparation. In addition, the subjects reported their personal best marathon time, defined as the fastest marathon race time ever achieved beforehand, independent of the race course and environmental conditions. Twelve marathoners and six 24-hour ultramarathoners dropped out in the time interval between recruitment and the race day. The athletes and the researcher were in email contact between recruitment and race day.

\section{Statistical analysis}

The data were analyzed using SPSS software version 15 (SPSS Inc, Chicago, IL). The data were checked for distribution of normality and are presented as the mean \pm standard deviation. The coefficient of variation (CV) of performance $(\mathrm{CV} \%=100 \times$ standard deviation/mean $)$ was calculated. The $\mathrm{CV}$ describes the magnitude of the sample values and the variation within them. Data for the 24-hour ultramarathoners and marathoners were compared using the Mann-Whitney U test. An alpha level of 0.05 was used to indicate a statistically significant difference. To investigate a potential association between anthropometric and training characteristics and 
race performance, as a first step, the relationship between marathon race time for the marathoners and the kilometers completed for the 24-hour ultramarathoners as the dependent variable and the variables of age, anthropometry, training, and previous experience was investigated using bivariate Pearson correlation analysis. In order to reduce the variables in the multivariate analysis, Bonferroni correction was applied ( $P<0.0023$ for 22 variables). In a second step, all variables identified as significant after bivariate analysis were entered into a multiple linear regression analysis (stepwise, forward selection, $P$ of $\mathrm{F}$ for inclusion $<0.05, P$ of $\mathrm{F}$ for exclusion $>0.1$ ). Multicollinearity between the predictor variables was excluded with $r>0.9$. A power calculation was performed according to the method reported by Gatsonis and Sampson. ${ }^{34}$ A sample of 40 participants was required to achieve a power of $80 \%$ (two-sided type I error of 5\%) and detect a minimal association between race time and anthropometric characteristics of $20 \%$ (ie, coefficient of determination $r^{2}=0.2$ ).

\section{Results}

Of the 126 marathoners, 92 (73\%) had already completed at least one marathon (mean $12 \pm 22$ marathons). Their personal best marathon time was $216 \pm 32$ minutes. For the 79 24-hour ultramarathoners, 74 (98\%) had already finished a marathon (mean $26 \pm 23$ marathons) with a mean personal best marathon time of $198 \pm 31$ minutes. The 24-hour ultramarathoners had completed significantly more marathons prerace $(P<0.0001)$; however, their personal best marathon time was not faster compared with the marathoners $(P>0.05)$.

\section{Performance of 24-hour ultramarathoners and marathoners}

The 24-hour ultramarathoners ran a distance of $144 \pm 43$ kilometers within the 24 hours, with a CV of performance of $29.5 \%$. Expressed as a percentage of the course record of $290.225 \mathrm{~km}$ set by Yannis Kouros in 1998, they achieved $49.8 \% \pm 15.0 \%$ of the record. While racing, they were running at a mean speed of $6.0 \pm 1.8 \mathrm{~km} /$ hour. The marathoners finished their marathon within $231 \pm 31$ minutes (CV 13.7\%), which is equal to approximately 3 hours 51 minutes. The mean performance of the marathoners represents $68.4 \%$ of the best performance of 2 hours 38 minutes set by Andreas Schur in 2010. The marathoners were running at a speed of $11.1 \pm 1.4 \mathrm{~km} /$ hour in the marathon, which was significantly faster than the 24-hour ultramarathoners in their 24-hour ultramarathon $(P<0.0001)$.

\section{Differences between 24-hour}

\section{ultramarathoners and marathoners}

The 24-hour ultramarathoners were older, had smaller upper arm and thigh circumferences and lower skinfold thickness at the pectoral, axillary, and suprailiac sites compared with the marathoners (Table 1). During training, the 24-hour ultramarathoners were running for more hours per week and completed more kilometers, but were running slower

Table I Comparison of anthropometry and training between 24hour ultramarathoners and marathoners

\begin{tabular}{|c|c|c|c|}
\hline & $\begin{array}{l}\text { 24-hour } \\
\text { ultramarathoners } \\
(n=79)\end{array}$ & $\begin{array}{l}\text { Marathoners } \\
(n=126)\end{array}$ & Difference \\
\hline Age (years) & $47.0 \pm 10.5$ & $42.8 \pm 10.8$ & $P<0.05$ \\
\hline Body mass (kg) & $72.8 \pm 7.6$ & $73.9 \pm 8.0$ & \\
\hline Body height $(\mathrm{m})$ & $1.77 \pm 0.07$ & $1.78 \pm 0.06$ & \\
\hline $\begin{array}{l}\text { Body mass } \\
\text { index }\left(\mathrm{kg} / \mathrm{m}^{2}\right)\end{array}$ & $23.0 \pm 1.7$ & $23.4 \pm 2.2$ & \\
\hline $\begin{array}{l}\text { Circumference of } \\
\text { upper } \operatorname{arm}(\mathrm{cm})\end{array}$ & $28.4 \pm 1.7$ & $29.2 \pm 1.9$ & $P<0.05$ \\
\hline $\begin{array}{l}\text { Circumference of } \\
\text { thigh }(\mathrm{cm})\end{array}$ & $53.3 \pm 3.3$ & $54.9 \pm 2.6$ & $P<0.01$ \\
\hline $\begin{array}{l}\text { Circumference of } \\
\text { calf }(\mathrm{cm})\end{array}$ & $37.9 \pm 2.2$ & $37.9 \pm 2.3$ & \\
\hline $\begin{array}{l}\text { Skinfold } \\
\text { pectoral (mm) }\end{array}$ & $7.1 \pm 3.2$ & $8.1 \pm 3.0$ & $P<0.05$ \\
\hline $\begin{array}{l}\text { Skinfold } \\
\text { axillary }(\mathrm{mm})\end{array}$ & $8.6 \pm 3.3$ & $9.6 \pm 2.8$ & $P<0.05$ \\
\hline $\begin{array}{l}\text { Skinfold } \\
\text { triceps }(\mathrm{mm})\end{array}$ & $7.9 \pm 2.5$ & $7.8 \pm 2.6$ & \\
\hline $\begin{array}{l}\text { Skinfold } \\
\text { subscapular }(\mathrm{mm})\end{array}$ & $10.5 \pm 4.2$ & $10.5 \pm 4.0$ & \\
\hline $\begin{array}{l}\text { Skinfold } \\
\text { abdominal }(\mathrm{mm})\end{array}$ & $16.5 \pm 7.9$ & $15.4 \pm 6.3$ & \\
\hline $\begin{array}{l}\text { Skinfold } \\
\text { iliac (mm) }\end{array}$ & $15.7 \pm 8.2$ & $18.3 \pm 7.1$ & $P<0.05$ \\
\hline $\begin{array}{l}\text { Skinfold } \\
\text { thigh }(\mathrm{mm})\end{array}$ & $12.5 \pm 7.4$ & $12.0 \pm 5.0$ & \\
\hline $\begin{array}{l}\text { Skinfold } \\
\text { calf }(\mathrm{mm})\end{array}$ & $6.4 \pm 2.7$ & $6.1 \pm 2.4$ & \\
\hline $\begin{array}{l}\text { Sum of } \\
\text { skinfolds }(\mathrm{mm})\end{array}$ & $85.1 \pm 32.0$ & $87.4 \pm 27.2$ & \\
\hline $\begin{array}{l}\text { Percent } \\
\text { body fat (\%) }\end{array}$ & $16.0 \pm 4.2$ & $16.2 \pm 3.7$ & \\
\hline $\begin{array}{l}\text { Skeletal } \\
\text { muscle mass }(\mathrm{kg})\end{array}$ & $37.0 \pm 3.8$ & $38.1 \pm 3.9$ & \\
\hline Years as runner & $13.5 \pm 8.8$ & $10.5 \pm 9.4$ & $P<0.05$ \\
\hline $\begin{array}{l}\text { Weekly } \\
\text { running hours }\end{array}$ & $9.1 \pm 5.0$ & $4.8 \pm 2.5$ & $P<0.001$ \\
\hline $\begin{array}{l}\text { Weekly running } \\
\text { kilometers }\end{array}$ & $86.5 \pm 35.9$ & $44.7 \pm 24.7$ & $P<0.001$ \\
\hline $\begin{array}{l}\text { Speed in } \\
\text { running training } \\
\text { (km/hour) }\end{array}$ & $10.2 \pm 1.5$ & $11.0 \pm 1.4$ & $P<0.01$ \\
\hline
\end{tabular}

Note: Results are presented as the mean \pm standard deviation. 
than the marathoners. In the 24-hour ultramarathoners, no anthropometric or training variables were associated with kilometers completed in the 24-hour ultramarathon after bivariate analysis (Table 2). For the marathoners, percent body fat and running speed during training were related to marathon race time in the multivariate analysis (Table 3 ). Running speed during training sessions was significantly and negatively correlated with percent body fat in the marathoners (Figure 1).

Due to the fact that the CV of performance was very high in the 24-hour ultramarathoners compared with the marathoners and neither anthropometric nor training variables were related to kilometers run over 24 hours, we performed a separate multivariate regression analysis including only the 24-hour ultramarathoners who had completed at least $100 \mathrm{~km}$ (CV 21.9\%) and $150 \mathrm{~km}$ (CV 14.5\%). No anthropometric or training variables were related to kilometers run over 24 hours in the 65 24-hour ultramarathoners who

Table 2 Association of anthropometric and training characteristics with race time for both the 24-hour ultramarathoners and the marathoners using bivariate analysis

\begin{tabular}{|c|c|c|c|c|}
\hline & \multicolumn{2}{|c|}{$\begin{array}{l}\text { 24-hour } \\
\text { ultramarathoners } \\
(n=79)\end{array}$} & \multicolumn{2}{|c|}{$\begin{array}{l}\text { Marathoners } \\
(n=126)\end{array}$} \\
\hline & $\mathbf{r}$ & $P$ & $\mathbf{r}$ & $P$ \\
\hline Age & 0.02 & 0.8 & 0.23 & 0.0096 \\
\hline Body mass & -0.25 & 0.03 & 0.24 & 0.0069 \\
\hline Body height & -0.17 & 0.1 & -0.01 & 0.95 \\
\hline Body mass index & -0.17 & 0.1 & 0.27 & 0.0019 \\
\hline $\begin{array}{l}\text { Circumference } \\
\text { of upper arm }\end{array}$ & -0.03 & 0.8 & 0.16 & 0.067 \\
\hline Circumference of thigh & -0.09 & 0.4 & 0.23 & 0.0088 \\
\hline Circumference of calf & -0.10 & 0.4 & 0.19 & 0.032 \\
\hline Skinfold pectoral & -0.23 & 0.04 & 0.36 & $<0.000$ I \\
\hline Skinfold axillary & -0.30 & 0.006 & 0.43 & $<0.000$ I \\
\hline Skinfold triceps & -0.21 & 0.06 & 0.23 & 0.0105 \\
\hline Skinfold subscapular & -0.23 & 0.04 & 0.26 & 0.0028 \\
\hline Skinfold abdominal & -0.28 & 0.01 & 0.37 & $<0.000$ I \\
\hline Skinfold suprailiac & -0.26 & 0.02 & 0.32 & 0.0003 \\
\hline Skinfold thigh & -0.15 & 0.2 & 0.34 & $<0.000$ I \\
\hline Skinfold calf & -0.05 & 0.6 & 0.42 & $<0.000$ I \\
\hline Sum of skinfolds & -0.28 & 0.01 & 0.43 & $<0.000$ I \\
\hline Percent body fat & -0.28 & 0.01 & 0.46 & $<0.000$ I \\
\hline Skeletal muscle mass & -0.07 & 0.5 & 0.04 & 0.67 \\
\hline Years as runner & 0.03 & 0.8 & -0.08 & 0.3 \\
\hline Weekly running hours & 0.13 & 0.3 & -0.20 & 0.027 \\
\hline $\begin{array}{l}\text { Weekly running } \\
\text { kilometers }\end{array}$ & 0.15 & 0.2 & -0.30 & 0.0007 \\
\hline $\begin{array}{l}\text { Speed in running } \\
\text { training }\end{array}$ & 0.27 & 0.01 & -0.61 & $<0.0001$ \\
\hline
\end{tabular}

Note: Variables with $P$ values of $<0.0023$ are inserted in the multivariate analysis ( $n=22$ variables).
Table 3 Associations between significant characteristics after bivariate analysis and race time for marathoners using multiple linear regression $(n=126)$

\begin{tabular}{llll}
\hline & $\boldsymbol{\beta}$ & $\mathbf{S E}$ & $\boldsymbol{P}$ \\
\hline Marathoners & & & \\
Body mass index & 0.6 & 1.0 & 0.5 \\
Percent body fat & 2.4 & 0.6 & 0.0002 \\
Kilometers run weekly & -0.1 & 0.1 & 0.2 \\
Speed in running training & $-1 \mathrm{I} .5$ & $\mathrm{I} .7$ & $<0.000 \mathrm{I}$ \\
24-hour ultramarathoners $(>\mathbf{I 0 0} \mathbf{~ k m})$ & & \\
Body mass index & -3.8 & 3.1 & 0.2 \\
Percent body fat & 1.1 & 1.9 & 0.6 \\
Kilometers run weekly & 0.3 & 0.1 & 0.07 \\
Speed in running training & 4.9 & 4.7 & 0.3 \\
24-hour ultramarathoners $(>\mathbf{I 5 0} \mathbf{~ k m )}$ & & \\
Body mass index & -2.1 & 2.7 & 0.4 \\
Percent body fat & -2.2 & 1.3 & 0.08 \\
Kilometers run weekly & 0.06 & 0.1 & 0.6 \\
Speed in running training & 2.7 & 2.9 & 0.3 \\
\hline
\end{tabular}

Notes: The coefficient of determination $\left(r^{2}\right)$ for the model was 0.47 . The same variables were used for the 24-hour ultramarathoners achieving more than $100 \mathrm{~km}$ within 24 hours $(n=65)$ and more than $150 \mathrm{~km}(n=35)$. No variable was significant in the 24-hour ultramarathoners; $r^{2}$ was 0.19 for both models.

Abbreviations: $\beta$, regression coefficient; SE, standard error of the regression coefficient.

ran more than 100 kilometers (Table 3 ) or in the 35 24-hour ultramarathoners completing more than 150 kilometers.

\section{Associations between performance and age, anthropometry, and training}

Age showed no association with performance in the 24-hour ultramarathoners $(r=0.02, P>0.05)$ (Table 2). However, in



Figure I In the marathoners $(\mathrm{n}=\mid 26)$, speed during running training was significantly and negatively related to percent body fat $(r=-0.32, P=0.0002)$. 
the marathoners, age was significantly and positively related to marathon race times $(r=0.23, P=0.0096)$. Because age, upper arm and thigh circumferences, skinfold thickness at the pectoral, axillary, and suprailiac sites, and training volume and speed were different between the 24-hour ultramarathoners and the marathoners, we investigated potential associations between these anthropometric and training variables for each group. While skinfold thickness was related to kilometers run each week and running speed during training in both the 24-hour ultramarathoners and the marathoners (Table 4), skinfold thickness was also related to weekly running hours in the marathoners. In addition, pectoral and axillary skinfold thickness was related to age in the marathoners.

\section{Discussion}

The aim of the present study was to compare age, anthropometric, and training characteristics between male recreational 24-hour ultramarathoners and male recreational marathoners. The primary outcome was that these two groups of athletes showed differences in age, upper arm and thigh circumference, and skinfold thickness at pectoral, axillary, and suprailiac sites. However, the marathoners invested less time in training but were training faster compared with the 24-hour ultramarathoners.

\section{Differences in anthropometry and training}

An important finding was that no anthropometric or training variables were related to kilometers run by the 24-hour ultramarathoners. This is in contrast with the marathoners, in whom percent body fat and running speed during training was associated with marathon race time. The present findings are also in contrast with those of a recent study comparing $100 \mathrm{~km}$ ultramarathoners and marathoners which showed that age, body mass, and percent body fat were positively related and kilometers run weekly were negatively related to $100 \mathrm{~km}$ race times in ultramarathoners. ${ }^{28}$ However, in marathoners, percent body fat was positively associated and training speed was negatively associated with marathon race times.

Differences in anthropometry and training between the two groups of athletes might explain these disparate findings. In the study comparing $100 \mathrm{~km}$ ultramarathoners and marathoners, the marathoners had a significantly lower calf circumference and significantly thicker skinfolds at the pectoral, axillary, and suprailiac sites compared with the $100 \mathrm{~km}$ ultramarathoners. ${ }^{28}$ Also, the marathoners ran for significantly fewer hours and covered significantly fewer kilometers during the week, but were running significantly faster during training. ${ }^{28}$ However, in the present investigation, none of the variables compared between the 24-hour ultramarathoners and the marathoners was related to race performance in either group after multivariate analysis.

Another explanation could be the performance of the athletes. We calculated $\mathrm{CV}$ for performance in order to compare the achievements of the runners. The CV in the 24-hour ultramarathoners was $29.5 \%$, which is considerably higher than the CV for performance of $13.7 \%$ in the marathoners. When we expressed the performance of the athletes as a percentage of the course record, the 24-hour ultramarathoners were approximately $50 \%$ below the longest distance achieved, whereas the marathoners were about $50 \%$ above the course record. Although the percentages were the same, we assume that the higher $\mathrm{CV}$ for the performance of 24-hour ultramarathoners compared with marathoners

Table 4 Association of anthropometric characteristics with age and training variables in 24-hour ultramarathoners $(n=79)$ and in marathoners $(n=126)$

\begin{tabular}{llllll}
\hline & Age & $\begin{array}{l}\text { Year as } \\
\text { active runner }\end{array}$ & $\begin{array}{l}\text { Kilometers } \\
\text { run weekly }\end{array}$ & $\begin{array}{l}\text { Weekly } \\
\text { hours run }\end{array}$ & $\begin{array}{l}\text { Running speed } \\
\text { during training }\end{array}$ \\
\hline 24-hour ultramarathoners & & & & & \\
Circumference of upper arm & $r=-0.16$ & $r=0.00$ & $r=-0.08$ & $r=0.01$ & $r=-0.03$ \\
Circumference of thigh & $r=-0.18$ & $r=-0.08$ & $r=-0.12$ & $r=0.08$ & $r=-0.07$ \\
Pectoral skinfold & $r=0.19$ & $r=0.00$ & $r=-0.27, P=0.01$ & $r=-0.01$ & $r=-0.5$ I, $P<0.000$ I \\
Axillary skinfold & $r=-0.05$ & $r=0.02$ & $r=-0.29, P=0.009$ & $r=-0.05$ & $r=-0.45, P<0.000$ I \\
Suprailiac skinfold & $r=-0.08$ & $r=0.00$ & $r=-0.30, P=0.007$ & $r=-0.16$ & $r=-0.31, P=0.005$ \\
Marathoners & & & & & \\
Circumference of upper arm & $r=-0.06$ & $r=0.13$ & $r=0.01$ & $r=-0.06$ & $r=-0.01$ \\
Circumference of thigh & $r=-0.05$ & $r=0.11$ & $r=0.05$ & $r=-0.07$ & $r=-0.03$ \\
Pectoral skinfold & $r=0.27, P=0.002$ & $r=0.08$ & $r=-0.23, P=0.01$ & $r=-0.19, P=0.03$ & $r=-0.24, P=0.007$ \\
Axillary skinfold & $r=0.23, P=0.01$ & $r=0.09$ & $r=-0.27, P=0.002$ & $r=-0.21, P=0.02$ & $r=-0.23, P=0.01$ \\
Suprailiac skinfold & $r=-0.01$ & $r=0.01$ & $r=-0.30, P=0.0006$ & $r=-0.18, P=0.04$ & $r=-0.25, P=0.005$ \\
\hline
\end{tabular}

Note: $R$ values represent Pearson correlation coefficients. $P$ values are provided in the event of a significant association. 
was the reason that none of the anthropometric or training variables were related to race performance in the 24-hour ultramarathon.

In a 24-hour ultramarathon, the runners do not have to finish a defined distance within a time limit, which is generally the opposite of what is expected in an endurance performance, and instead have to cover the greatest possible distance within 24 hours. Therefore, the athletes can run more slowly or as fast as possible and take breaks or go to sleep when they want. If an athlete suffers from an overuse injury or has another medical problem, such as dehydration or a digestive problem, the athlete can stop, solve the problem, and continue the race. When an athlete stops running before the 24 hours are over, the kilometers completed are considered to be that athlete's race performance and the athlete is ranked in the final race results. This may explain the large CV for performance of $29.5 \%$ in the present 24-hour ultramarathoners. The large $\mathrm{CV}$ in performance and the rather weak performance of about $145 \mathrm{~km}$, varying from $63 \mathrm{~km}$ to $238 \mathrm{~km}$ over 24 hours, compared with the $199 \mathrm{~km}$ in the study of $\mathrm{Kao}$ et $\mathrm{al}^{4}$ with distances between $127 \mathrm{~km}$ and $261 \mathrm{~km}$, might also be an indicator of motivational problems. ${ }^{7}$

When we investigated body mass index, body fat, kilometers run per week, and running speed during training as potentially predictive variables for 24-hour ultramarathoners completing more than 100 kilometers or more than 150 kilometers, none of the anthropometric or training variables was related to the kilometers achieved over the 24 hours. Although the CV for performance dropped, the $\mathrm{CV}$ in the multivariate regression model did not change. We assume that other predictive variables, such as personal best marathon time and differences in running economy ${ }^{35}$ are more important than anthropometric characteristics and training in a 24-hour race. ${ }^{5,12}$ Another explanation may be that the $\mathrm{CV}$ differed according to the type of test (ie, a constant duration test, constant distance test, or constant velocity test) as discussed by Coquart and Garcin. ${ }^{36}$ During a marathon, the athletes take no breaks, whereas during a 24-hour ultramarathon, athletes may make breaks to change clothes and to eat. Indeed, the constant duration test reported a low CV of about $3 \%^{37}$ in comparison with constant velocity tests, with the $\mathrm{CV}$ between $5.2 \%$ and $55.9 \%,{ }^{38}$ whereas a $\mathrm{CV}$ in the constant distance test is approximately $2 \%$.

A further potential explanation for these differences might be the difference in age. The marathoners were younger than the 24-hour ultramarathoners. In $100 \mathrm{~km}$ ultramarathoners, running speed during training, training volume, and age have been shown to predict race time. ${ }^{8}$ However, in marathoners, percent body fat and running speed but not age were predictive. ${ }^{39}$ In addition, the weather during the 24-hour ultramarathon with temperatures changing between day and night might have had an important influence. ${ }^{40}$

\section{Associations between anthropometric characteristics and training}

A further finding was the difference in skinfold thickness between the two groups of athletes, indicating different relationships with training characteristics. Skinfold thickness at the pectoral, axillary, and suprailiac sites was related to both kilometers run per week and running speed during training in both the 24-hour ultramarathoners and the marathoners, and skinfold thickness at the same sites was also related to hours run per week in the marathoners.

Legaz and Eston ${ }^{41}$ showed that training resulted in a significant increase in performance and a significant decrease in the sum of six abdominal, front thigh, and medial calf skinfold thicknesses in top class runners. Correlation analysis does not demonstrate cause and effect, so low skinfold thickness is not necessarily due to training. Low skinfold thickness and low body fat in endurance athletes can also be the result of diet. ${ }^{42}$

\section{Limitations and practical applications}

This study has some limitations. We did not include general weather conditions because both marathon ${ }^{43-45}$ and ultramarathon ${ }^{40,46}$ performance can be influenced by environmental temperature. Also, nutrition ${ }^{47}$ and fluid intake ${ }^{48}$ may affect ultraendurance performance, and inclusion of physiological variables ${ }^{49}$ might be important in predicting running performance. Self-reporting of times and distances during training was a limitation because we had no way of establishing the reliability and precision of reporting. For future research, the reliability of training data might be enhanced by quantifying and validating self-reported training data using a global positioning system. Based on the present findings, recreational marathoners and 24-hour ultramarathoners are not comparable regarding their anthropometry and training. However, any runner aiming to achieve needs to have broad experience in running, invest about 9 hours per week in running training, run at about $10 \mathrm{~km} /$ hour during training, and run approximately 90 kilometers per week.

\section{Conclusion}

To summarize, 24-hour ultramarathoners and marathoners showed minor differences in limb circumference and skinfold thickness, but major differences in training variables. 
The largest difference found was that there was no predictive variable for 24-hour ultramarathoners. However, lower body fat and a higher running speed during training were related to a faster marathon race time in marathoners. Although personal best marathon time has been reported to be a strong predictive variable for recreational 24-hour ultramarathoners, the recreational marathoners and recreational 24-hour ultramarathoners in our study were not comparable regarding their anthropometry and training.

\section{Disclosure}

The authors declare that they have no competing interests in this work.

\section{References}

1. Hoffman MD, Wegelin JA. The Western States 100-mile endurance run: participation and performance trends. Med Sci Sports Exerc. 2009;41: 2191-2198.

2. Hoffman MD. Performance trends in 161-km ultramarathons. Int $J$ Sports Med. 2010;31:31-37.

3. Hoffman MD, Ong JC, Wang G. Historical analysis of participation in $161 \mathrm{~km}$ ultramarathons in North America. Int J Hist Sport. 2010;27: 1877-1891.

4. Kao WF, Shyu CL, Yang XW, et al. Athletic performance and serial weight changes during 12- and 24-hour ultra-marathons. Clin J Sport Med. 2008;18:155-158.

5. Knechtle B, Wirth A, Knechtle P, Zimmermann K, Kohler G. Personal best marathon performance is associated with performance in a 24-h run and not anthropometry or training volume. Br J Sports Med. 2009;43: $836-839$.

6. Knechtle B, Duff B, Welzel U, Kohler G. Body mass and circumference of upper arm are associated with race performance in ultraendurance runners in a multistage race - the Isarrun 2006. Res Q Exerc Sport. 2009;80:262-268.

7. Knechtle B, Duff B, Schulze I, Rosemann T, Senn O. Anthropometry and pre-race experience of finishers and non-finishers in a multistage ultra-endurance run - Deutschlandlauf 2007. Percept Mot Skills. 2009;109:105-118.

8. Knechtle B, Knechtle P, Rosemann T, Lepers R. Predictor variables for a $100-\mathrm{km}$ race time in male ultra-marathoners. Percept Mot Skills. 2010;111:681-693.

9. Knechtle B, Knechtle P, Rosemann T. Race performance in male mountain ultra-marathoners: anthropometry or training? Percept Mot Skills. 2010;110:721-735.

10. Knechtle B, Wirth A, Knechtle P, Rosemann T. Training volume and personal best time in marathon, not anthropometric parameters, are associated with performance in male 100-km ultrarunners. J Strength Cond Res. 2010;24:604-609.

11. Knechtle B, Knechtle P, Rosemann T, Senn O. What is associated with race performance in male 100-km ultra-marathoners - anthropometry, training or marathon best time? J Sports Sci. 2011;29:571-577.

12. Knechtle B, Knechtle P, Rosemann T, Lepers R. Personal best marathon time and longest training run, not anthropometry, predict performance in recreational 24-hour ultrarunners. J Strength Cond Res. 2011;25: 2212-2218.

13. Knechtle B, Knechtle P, Rüst CA, Rosemann T. Leg skinfold thicknesses and race performance in male 24-hour ultra-marathoners. Proc (Bayl Univ Med Cent). 2011;24:110-114.

14. Millet GY, Banfi JC, Kerherve H, et al. Physiological and biological factors associated with a $24 \mathrm{~h}$ treadmill ultra-marathon performance. Scand J Med Sci Sports. 2011;21:54-61.
15. Noakes TD, Myburgh KH, Schall R. Peak treadmill running velocity during the $\mathrm{VO}_{2}$ max test predicts running performance. J Sports Sci. 1990;8:35-45.

16. Knechtle B, Rüst CA, Rosemann T, Lepers R. Age-related changes in 100-km ultra-marathon running performance. Age (Dordr). 2012;34: 1033-1045.

17. Skenderi KP, Kavouras SA, Anastasiou CA, Yiannakouris N, Matalas AL. Exertional rhabdomyolysis during a 246-km continuous running race. Med Sci Sports Exerc. 2006;38:1054-1057.

18. Zouhal H, Groussard C, Vincent S, et al. Athletic performance and weight changes during the "Marathon of Sands" in athletes well-trained in endurance. Int J Sports Med. 2009;30:516-521.

19. http://www.ultramarathonrunning.com/races/index.html. Accessed February 2, 2012

20. Legaz Arrese A, Munguía Izquierdo D, Serveto Galindo JR. Physiological measures associated with marathon running performance in high-level male and female homogeneous groups. Int J Sports Med. 2006;27:289-295.

21. Hagan RD, Smith MG, Gettman LR. Marathon performance in relation to maximal aerobic power and training indices. Med Sci Sports Exerc. 1981;13:185-189.

22. Hagan RD, Upton SJ, Duncan JJ, Gettman LR. Marathon performance in relation to maximal aerobic power and training indices in female distance runners. Br J Sports Med. 1987;21:3-7.

23. Loftin M, Sothern M, Koss C, et al. Energy expenditure and influence of physiologic factors during marathon running. J Strength Cond Res. 2007;21:1188-1191.

24. Arrese AL, Ostáriz ES. Skinfold thicknesses associated with distance running performance in highly trained runners. J Sports Sci. 2006;24: 69-76.

25. Knechtle B, Knechtle P, Barandun U, Rosemann T, Lepers R. Predictor variables for half marathon race time in recreational female runners. Clinics (Sao Paulo). 2011;66:287-291.

26. Yeung SS, Yeung EW, Wong TW. Marathon finishers and non-finishers characteristics. A preamble to success. J Sports Med Phys Fitness. 2001;41:170-176.

27. McKelvie SJ, Valliant PM, Asu ME. Physical training and personality factors as predictors of marathon time and training injury. Percept Mot Skills. 1985;60:551-566.

28. Rüst CA, Knechtle B, Knechtle P, Rosemann T. Similarities and differences in anthropometry and training between recreational male 100-km ultra-marathoners and marathoners. J Sports Sci. 2012;30: 1249-1257.

29. Knechtle B, Knechtle P, Lepers R. Participation and performance trends in ultra-triathlons from 1985 to 2009. Scand J Med Sci Sports. 2011;21: e82-e90.

30. Becque MD, Katch VL, Moffatt RJ. Time course of skin-plus-fat compression in males and females. Hum Biol. 1986;58:33-42.

31. Knechtle B, Joleska I, Wirth A, Knechtle P, Rosemann T, Senn O. Intra- and inter-judge reliabilities in measuring the skin-fold thicknesses of ultra runners under field conditions. Percept Mot Skills. 2010;111: 105-106.

32. Ball SD, Altena TS, Swan PD. Comparison of anthropometry to DXA: a new prediction equation for men. Eur J Clin Nutr. 2004;58: 1525-1531.

33. Lee RC, Wang Z, Heo M, Ross R, Janssen I, Heymsfield SB. Total-body skeletal muscle mass: development and cross-validation of anthropometric prediction models. Am J Clin Nutr. 2000;72:796-803.

34. Gatsonis C, Sampson AR. Multiple correlation: exact power and sample size calculations. Psychol Bull. 1989;106:516-524.

35. Beneke R, Hütler M. The effect of training on running economy and performance in recreational athletes. Med Sci Sports Exerc. 2005;37: 1794-1799.

36. Coquart JB, Garcin M. Validity and reliability of perceptually-based scales during exhausting runs in trained male runners. Percept Mot Skills. 2007;104:254-266.

37. Jeukendrup A, Saris WH, Brouns F, Kester AD. A new validated endurance performance test. Med Sci Sports Exerc. 1996;28: 266-270. 
38. Krebs PS, Power SK. Reliability of endurance tests. Med Sci Sports Exerc. 1989;21:S10.

39. Barandun U, Knechtle B, Knechtle P, et al. Running speed during training and percent body fat predict race time in recreational male marathoners. Open Access J Sports Med. 2012;3:51-58.

40. Parise CA, Hoffman MD. Influence of temperature and performance level on pacing a $161 \mathrm{~km}$ trail ultramarathon. Int J Sports Physiol Perform. 2011;6:243-251.

41. Legaz A, Eston R. Changes in performance, skinfold thicknesses, and fat patterning after three years of intense athletic conditioning in high level runners. Br J Sports Med. 2005;39:851-856.

42. Rodriguez NR, Di Marco NM, Langley S; American Dietetic Association; Dietitians of Canada; American College of Sports Medicine. American College of Sports Medicine position stand. Nutrition and athletic performance. Med Sci Sports Exerc. 2009;41:709-731.

43. Ely MR, Cheuvront SN, Roberts WO, Montain SJ. Impact of weather on marathon-running performance. Med Sci Sports Exerc. 2007;39: 487-493.
44. Trapasso LM, Cooper JD. Record performances at the Boston Marathon: biometeorological factors. Int J Biometeorol. 1989;33:233-237.

45. Vihma T. Effects of weather on the performance of marathon runners. Int J Biometeorol. 2010;54:297-306.

46. Wegelin JA, Hoffman MD. Variables associated with odds of finishing and finish time in a 161-km ultramarathon. Eur J Appl Physiol. 2011; 111:145-153.

47. Maughan RJ, Shirreffs SM. Nutrition for sports performance: issues and opportunities. Proc Nutr Soc. 2011;17:1-8.

48. Von Duvillard SP, Arciero PJ, Tietjen-Smith T, Alford K. Sports drinks, exercise training, and competition. Curr Sports Med Rep. 2008;7: 202-208.

49. Billat VL, Demarle A, Slawinski J, Paiva M, Koralsztein JP. Physical and training characteristics of top-class marathon runners. Med Sci Sports Exerc. 2001;33:2089-2097.

\section{Publish your work in this journal}

Open Access Journal of Sports Medicine is an international, peer-reviewed, open access journal publishing original research, reports, reviews and commentaries on all areas of sports medicine. The manuscript management system is completely online and includes a very quick and fair peer-review system.

\section{Dovepress}

Visit http://www.dovepress.com/testimonials.php to read real quotes from published authors. 